\title{
Governança corporativa: a situação das empresas brasileiras em relação às melhores práticas
}

\author{
Corporate governance: the state of Brazilian corporations in \\ relation to best practices
}

\section{Antonio Guilherme de Arruda Lorenzi ${ }^{[a]}$, Mario Procopiuck ${ }^{[\mathrm{b}]}$, Carlos Olavo Quandt ${ }^{[\mathrm{c}]}$}

[a] Mestre em Tecnologia pela Universidade Tecnológica Federal do Paraná (UTFPR), Doutorando em Administração na Pontifícia Universidade Católica do Parana (PUCPR), Curitiba, PR - Brasil, e-mail: guilherme_lorenzi@yahoo.com.br

[b] Mestre em Gestão Urbana pela Pontifícia Universidade Católica do Paraná, Doutorando em Administração pela Pontifícia Universidade Católica do Parana (PUCPR), Curitba, PR - Brasil, e-mail: mario.p@pucpr.br

[c] Pós-Doutorado pela University of California, San Diego, professor titular da Pontifícia Universidade Católica do Paraná (PUCPR), Curitiba, PR - Brasil, e-mail: carlos.quandt@pucpr.br

\section{Resumo}

O conceito de governança corporativa nasceu com o objetivo de fornecer maior nível de transparência em relação às empresas de capital aberto. Contudo, passou a ser entendido como de fundamental importância para o sucesso das organizações em geral, desafiando-as a se tornarem mais transparentes, socialmente responsáveis e capazes de se reportar com eficácia aos seus gestores e stakeholders, sejam do setor público ou privado, de empresas ou universidades. O tema da governança corporativa significa, entre outros aspectos, compreender que as organizações são regidas por diversas instâncias, cada uma com seus próprios critérios de gestão. Nessa linha, analisa-se a situação das práticas de governança corporativa no Brasil diante de práticas em outros grupos de países. Adotou-se como base recomendações de boas práticas para o Brasil, comparadas com aquelas elaboradas por outros grupos de países. Como tais recomendações são elaboradas em termos ideais, procurou-se avaliar a efetividade de sua aplicação, principalmente no Brasil, mediante análise das diferentes perspectivas da literatura que trata do tema. Com exceção de algumas iniciativas pontuais de sucesso, as evidências empíricas demonstram grandes fragilidades quanto ao desenvolvimento e à institucionalização de boas práticas de governança corporativa no Brasil.

Palavras-chave: Governança corporativa. Estratégia. Gestão. 


\begin{abstract}
The concept of corporate governance originated from the need to increase transparency for publicly traded companies. However, it is now seen as extremely important for the success of organizations as a whole, challenging them to become more transparent, socially responsible and accountable to their directors and stakeholders, be them from the public or private sector, companies or universities. The concept of corporate governance means, among other aspects, to understand that organizations are ruled by many instances, each one with their own governance criteria. Along those lines, we analyze the state of governance practices in Brazil in relation to practices in other groups of countries. Recommendations of good practices for Brazil were compared with those that were developed elsewhere. Since such recommendations are developed in ideal terms, the effectiveness of their application, particularly in Brazil, was analyzed in view of different perspectives found in the literature. Despite some successful initiatives, the evidence shows that the development and institutional embeddedness of corporate governance practices in Brazil still leaves much to be desired.
\end{abstract}

Keywords: Corporate governance. Strategy. Management.

\section{Introdução}

Não obstante as marcantes transformações contemporâneas, muitas organizações ainda não se afastaram totalmente dos princípios gerenciais definidos nas primeiras décadas do século passado. Ainda são comuns estruturas hierárquicas baseadas na lógica do comando-controle, na estratificação funcional em múltiplos níveis, em divisões funcionais, na definição formal de papéis e recompensas, com atenção mais voltada para processos internos que para o contexto em que se inserem. Tais perspectivas do pensamento e ação administrativos sem duvida deixaram contribuições para sedimentação de princípios modernos de organização. Isso ocorreu inicialmente com a incorporação da racionalidade para estruturação das atividades internas e, gradativamente, pela sua adaptação ao contexto social, econômico e tecnológico em acelerada evolução.

$\mathrm{Na}$ atualidade, com maior ou menor intensidade, em diferentes organizações, traços de princípios clássicos se mesclam a novas abordagens na definição de estruturas e formas complexas, tanto na configuração institucional quanto na concepção de novos sistemas de gestão e de governança. Observa-se uma crescente preocupação com a valorização do contexto social em que se insere o "negócio" da organização; a flexibilização nos processos gerenciais e decisórios; as mudanças nos processos de trabalho em função da incorporação tecnológica; a abertura de espaços para crescente influência dos clientes ou usuários na definição do produto final da organização, consonante com valores de uma sociedade em evolução; e a definição de sistemas de governança para pautar ações interorganizacionais em espaços que já não se conformam com fronteiras tradicionalmente delimitadas.

Este trabalho analisa a situação das práticas de governança corporativa no Brasil em comparação ao que se observa em outros contextos. As recomendações de boas práticas para o Brasil são comparadas com aquelas elaboradas por outros grupos de países. Como tais recomendações são elaboradas em termos ideais, procurou-se avaliar a efetividade de sua aplicação, principalmente no Brasil, mediante análise das diferentes perspectivas da literatura que trata do tema.

A compreensão dos diferentes papéis de agentes que atuam na organização ou que exercem influências sobre ela é essencial para compreender a organização como um ente coletivo capaz de agir estrategicamente. No seu contexto interno, o agente é representado por um indivíduo com capacidade de produzir e conduzir realizações sob influências ambientais e culturais de contextos mais amplos. As organizações resultam da constante construção e reconstrução dos processos que as estruturam por obra de seus próprios agentes ao atuarem imersos em complexas estruturas sociais que as circundam (MEYER; JEPPERSON, 2000). Desse modo, as organizações não se limitam a um microambiente isolado do contexto social (TSOUKAS, 1998, p. 297). Num contexto competitivo, são desafiadas a desenvolver estratégias que priorizem a competência organizacional e, ao mesmo tempo, fortaleçam sua capacidade de resposta às diversas demandas sociais (MEYER Jr., 2007, p. 266-267). 


\section{Compreensão das relações intra e interorganizacionais sob a ótica da governança}

As organizações representam mais do que meros instrumentos para atingir determinados objetivos: elas se posicionam como atores com direitos próprios, que podem agir, utilizar-se de recursos, firmar contratos e deter propriedades. O entendimento da extensão ocupada por elas na sociedade e do seu poder de interferência na definição de seus próprios cursos de ação requer que sejam consideradas suas relações com outros atores. Essas relações estruturam um ambiente social básico em que, por meio de comunicação e socialização, tem origem a formação de normas e o exercício do poder para ajustamento e alcance de objetivos (SCOT'T, 1992, p. 7-8).

As organizações, quando consideradas como sistemas abertos, são dependentes do fluxo de recursos e de informações provenientes do ambiente em que se incorporam. A sobrevivência nesse meio passa a depender de sua capacidade de induzir diversos outros agentes organizacionais a contribuir com tempo e energia. A indução nesse sentido é sustentada por sistemas de barganhas com objetivos de obtenção de recursos para serem alocados na consecução de seus propósitos (SCOTT, 1992, p. 25).

Para entender a dinâmica organizacional nesse meio relacional, é necessário considerar como se desenvolvem as interações recursivas entre diferentes atores que, por meio de decisões, definem o ambiente social (TSOUKAS, 1998, p. 302). O contexto estruturado em função das naturezas diversas das relações entre organizações é um importante elemento para a compreensão do ambiente em que se inserem. Nele são consideradas relações entre organizações privadas e públicas em âmbitos locais, regionais e globais (MEYER Jr., 2007, p. 270-271). Os arranjos de governança têm merecido crescente e expressiva atenção no esforço para compreender essas relações.

As organizações, com a finalidade de alinhar questões de natureza puramente econômica, sob as quais estruturam internamente suas relações, considerando os objetivos e interesses de outras organizações que atuam no mercado, têm que judiciosamente escolher e desenvolver sistemas de governança com base em pressupostos do mercado, da hierarquia ou de modelos híbridos entre esses dois extremos. Reconhecem, com isso, a natureza incompleta dos contratos puramente econômicos e procuram nas estruturas de governança um meio para preenchimento de lacunas que emergem do embate entre diferentes interesses envolvidos nas transações (WILLIAMSON, 1988). Evidentemente, as estruturas não existem de maneira independente dos agentes, pois as experiências destes nos sistemas de governança têm efeito crucial no comportamento da organização perante a sociedade e nas relações contratuais com suas congêneres. Desse modo, os agentes tentam negociar estrategicamente as limitações estruturais para maximizar sua autonomia e suas vantagens (PROCOPIUCK; FREY, 2009).

$\mathrm{Na}$ prática, existem grandes dificuldades práticas na estruturação de arranjos de governança das relações públicas e privadas em âmbito local, regional, nacional ou internacional. Para que haja governança, a sociedade deve estar diferenciada funcionalmente em subsistemas, em organizações especializadas e autônomas, especialmente quanto ao controle político, e com capacidade de levar a cabo funções sociais e econômicas importantes. Entre os diferentes grupos sociais e organizações, deve existir pelo menos um sentido de identidade comum e de responsabilidade com a totalidade. Para que surjam espaços profícuos para emergência e sedimentação da nova governança, cada agente corporativo tem de ser eficiente em sua própria esfera, sem que um consiga dominar os demais. Além disso, devem cooperar na formulação de políticas, em vez de apenas lutarem entre si (MAYNTZ, 2001; 2003).

\section{Governança corporativa}

Partindo de um contexto amplo das relações organizacionais, a economia de um país depende do desenvolvimento e da aplicação de sistemas de gestão capazes de fazer com que as companhias operem com eficiência e eficácia na consecução dos seus objetivos. Assim, a eficácia do exercício das responsabilidades das organizações determina, em última instância, a posição competitiva da própria nação. A liberdade dos dirigentes é condição indispensável para o pleno desenvolvimento das potencialidades de cada organização, mas tal exercício crescentemente deixa de ser incondicionado, e passa a ser parametrizado por princípios de responsabilidade e transparência perante diferentes stakeholders. Essa tem sido a essência de qualquer sistema da boa governança corporativa (CADBURY REPORT, 1992). 
Nessa linha, a governança corporativa passa a vista como parte do contexto econômico geral em que as empresas operam e que inclui, por exemplo, políticas macroeconômicas e o nível de concorrência em mercados de produtos e de fatores de produção. A estrutura da governança corporativa também depende do ambiente jurídico, regulamentar e institucional. Além disso, fatores como ética empresarial e percepção dos interesses ambientais e sociais das comunidades em que a empresa opera também afetam a imagem e o sucesso da corporação a longo prazo (OECD, 2004).

Nessa perspectiva, os sistemas de governança corporativa compreendem regras formais e informais, tanto públicas quanto privadas, aliadas a práticas aceitas e a mecanismos eficientes para impor sua execução. O desafio, portanto, está em transformar os arranjos políticos e econômicos de governança de sistemas fundamentados em relacionamentos para sistemas baseados em regras claras e com efetividade na aplicação (OMAN; BLUME, 2005).

A implementação de regulação consistente para os sistemas de governança enfrenta problemas decorrentes dos diferentes níveis de poder e influência, da propriedade e controle concentrados, e da existência de mecanismos que permitam um mínimo de proteção institucional aos acionistas minoritários. Não agir em face dessas dificuldades pode, direta ou indiretamente, corroborar situações com potencial de levar a baixas avaliações da firma, baixos níveis de pagamento de dividendos, adoção de estratégias ineficientes, baixos investimentos em inovação e, em muitos casos, expropriação de acionistas minoritários (YOUNG et al., 2008). Diante disso, a geração de legitimidade e confiança mediante aplicação das ideias e mecanismos de transparência e de accountability, elementos básicos da governança corporativa, ganha importância na medida em que o poder das corporações afeta, direta ou indiretamente, a vida de milhões de pessoas que, apesar de as sustentarem, ainda possuem pouca influência nas suas decisões, querindividual quercoletivamente (CASTIGLIONE, 2007, p. 6).

O grau em que as corporações genuinamente priorizam comportamentos socialmente responsáveis e facilitam influências dos stakeholders no sistema de gestão é questionável, considerando o formidável poder das corporações e os objetivos de lucros que estruturam suas prioridades (BROWNE, 2007, p. 163). A governança corporativa pode ser vista como o meio pelo qual a companhia se responsabiliza para dirigir e controlar os seus assuntos de maneira considerada justa pelos seus stakeholders. É importante observar que a visão de quem são os stakeholders varia entre contextos institucionais. Em alguns há uma visão bastante ampla dos constituintes desse grupo, ao passo que em outros contextos o enfoque recai quase exclusivamente sobre os acionistas (KOLK, 2008, p. 2).

Governança corporativa é definida por Lodi (2000, p. 19) como "o papel que os conselhos de administração passaram a exercer para melhorar o ganho dos acionistas e arbitrar os conflitos existentes entre os acionistas, administradores, auditores externos, minoritários, conselhos fiscais (no Brasil) e os stakeholders: empregados, credores e clientes". Note-se que, peculiarmente, nesse conceito há separação entre proprietários, administradores e controladores e stakeholders.

Nessa última perspectiva, em geral, o debate de governança corporativa tem se concentrado em mecanismos internos destinados prioritariamente a prover maior transparência de informações para fornecedores de finanças. Isso não significa, contudo, que a importância dos stakeholders em geral seja negada, mas o conjunto considerado explicitamente é composto por um número limitado. Até mesmo códigos internacionais como o da OCDE (2004) e da International Corporate Governance Network (2003) se limitam a mencionar explicitamente, além de acionistas, empregados è̀s vezes também gerentes (KOLK, 2008, p. 2).

A propriedade concentrada, combinada com a ausência de mecanismos de governança externos eficazes, tende a resultar em frequentes conflitos entre acionistas controladores, acionistas minoritários e gestores. Nesse ponto reside o motivo e a origem do desenvolvimento de uma nova perspectiva na governança corporativa, que se concentra nos conflitos entre stakeholders pertencentes a diferentes esferas internas e externas da organização (YOUNG et al., 2008, p. 197). Na verdade, isso acaba sendo reflexo do fato de as companhias crescentemente passarem a desempenhar, em âmbito macro, um papel fundamental nas economias e, em patamar micro, estar sendo confiado às instituições do setor privado a gestão de economias pessoais; logo, a boa governança corporativa passa a ser um elemento de considerável importância para crescentes segmentos da população (JOHNSTON, 2004, p. 3). 
Em tentativas mais recentes de fortalecer a governança corporativa mediante elevação do nível de accountability, em especial depois de escândalos como os das empresas Enron, WorldCom, Ahold e Parmalat, passa-se também a enfocar mecanismos internos que permitam avaliar a atuação de conselhos, gerentes, auditores e de sistemas de controle de riscos. Com isso, busca-se aumentar a percepção e a influência do acionista quanto ao comportamento corporativo no que diz respeito aos grandes problemas que permeiam os negócios. Também tem havido inclusão, por um lado, de aspectos éticos relacionados à remuneração, à gestão e ao comportamento de empregados e, por outro, passa-se a considerar concomitantemente stakeholders que compõem os amplos sistemas de governança em que a organização se insere (ROSSOUW, 2005; KOLK, 2008, p. 3).

Embora "a governança corporativa esteja se tornando crescentemente central nas estratégias de desenvolvimento em âmbito global" (SULLIVAN; SAMBUNARIS, 2005, p. 20), o conceito de governança corporativa é relativamente novo, tanto no Brasil como no mundo, muito embora ele venha sendo praticado, em maior ou menor escala, já há algumas décadas com outras nomenclaturas.

A Inglaterra, por exemplo, definiu as responsabilidades do conselheiro de administração desde os tempos vitorianos, no Companies Act, a sua Lei das Sociedades Anônimas, que marcou o mercado de capitais daquele país em todo o século XX. Mantendo a tradição e acentuando a importância das práticas de governança corporativa, o governo trabalhista criou um grupo de trabalho para a reforma da Lei das Companhias, a fim de reger a entrada no século XXI (LODI, 2000).

O conceito de governança corporativa, em termos globais, ganhou consistência nas duas últimas décadas, principalmente em economias de mercado em que a eficiência e a competitividade das firmas passaram a ser grandemente influenciadas pelas formas como se configura a sua propriedade e como são governadas (LIN, 2001, p. 6). O modelo predominante da governança corporativa é um produto de economias desenvolvidas, principalmente os Estados Unidos e o Reino Unido, onde o contexto institucional permite a execução relativamente eficiente de contratos de agência entre proprietários e gestores (YOUNG et al., 2008, p. 196).

O conceito de governança corporativa nasceu e ganhou força especialmente com a ascensão dos fundos de pensão, dos administradores de ativos e dos bancos, e a consequente reestruturação das relações entre acionistas, o conselho e o executivo principal (LODI, 2000, p. 34). Como é natural em qualquer processo evolutivo, não obstante os esforços empreendidos por diferentes instituições e pelo empresariado, o desenvolvimento e a sedimentação da governança corporativa no Brasil têm sido irregular e inconstante (STEINBERG, 2003). Embora o termo governança corporativa ainda seja novo, em processo de institucionalização

já há algum tempo no Brasil, deixou de ser assunto para criticar ou comentar os escândalos contábeis e financeiros que ocorreram nos Estados Unidos no início deste século. Hoje, muito dificilmente uma empresa terá sucesso em oferecer suas ações ou outras formas de títulos mobiliários ao mercado de capitais, ou mesmo obterá financiamentos com taxas de juros reduzidas ou investimentos de uma instituição financeira, sem demonstrar a sua aderência e aplicação a um mínimo de boas práticas de governança corporativa (KPMG, 2007, p. 2).

Na definição de um sistema de governança, num primeiro nível, torna-se essencial separar as decisões de gestão no âmbito interno da firma das decisões de controle situadas na esfera de atuação dos conselhos de diretores (WILLIAMSON, 1988). Contudo, na medida em que as organizações são dependentes da captação de recursos dispersos na sociedade, os próprios conselhos de diretores devem procurar meios legítimos de atuação externa da organização em consonância com princípios socialmente aceitos.

Especialmente depois do colapso da Enron, em 2001, em função de falhas sistêmicas de governança (CIFRINO et al., 2004), elevaram-se os níveis de demanda por estruturas de governança mais públicas, transparentes e inclusivas na gestão do capital privado. Diante disso, o movimento de governança corporativa passou a trazer duas questões fundamentais a serem compreendidas: como e para quem as corporações são dirigidas.

Portanto, a perspectiva da governança transcende o contexto prévio em que vigorava absoluta a autonomia corporativa capitalista. Os limites das esferas públicas e privadas são desafiados na medida 
em que as corporações passam a ser depositárias de recursos com propriedade compartilhada entre crescente número de pequenos acionistas, cujo perfil e interesses em muito se assemelham com os do próprio cidadão (BRENNAN, 2003, p. 43-44). Como consequência natural dessa aproximação surge a necessidade de ajustar comportamentos puramente econômicos destinados à maximização do lucro, de modo que as decisões organizacionais passem também a considerar variáveis sociais e políticas.

\section{Abordagens de governança corporativa}

A governança corporativa refere-se ao modo como companhias são governadas ou dirigidas e sua importância reside no fato de referir-se à gestão da mais importante instituição das economias capitalistas (PRABHAKAR, 2007). A separação entre propriedade e controle em grandes companhias leva à necessidade da governança corporativa, vista como um conjunto de mecanismos complementares que busca a proteção dos direitos de investidores e a redução do oportunismo administrativo. As práticas de governança corporativas variam em função de peculiaridades de diferentes ambientes institucionais, refletindo diferenças de cultura, e são condicionadas por opções em relação às finanças tradicionais e pela configuração de arcabouços legais localizados (ZAT'TONI; CUOMO, 2008, p. 1).

A governança corporativa tem por objeto as práticas e os relacionamentos entre acionistas, conselho de administração, diretoria, auditoria independente e conselho fiscal, com propósito de melhorar o desempenho da empresa, facilitar o acesso ao capital e proporcionar aos acionistas uma gestão estratégica e a efetiva monitoração da direção executiva da empresa. Nessa direção, formalmente, o Instituto Brasileiro de Governança Corporativa IBGC (2004) a define nos seguintes termos:

governança corporativa éo sistema pelo qual as sociedades são dirigidas e monitoradas, envolvendo os relacionamentos entre acionistas/ cotistas, conselho de administração, diretoria, auditoria independente e conselho fiscal. As boas práticas de governança corporativa têm a finalidade de aumentar o valor da sociedade, facilitar seu acesso ao capital e contribuir para a sua perenidade.
Além da preocupação com o contexto interno da organização, novas instituições têm emergido para o exercício de controle, evoluindo de estruturas para sistemas de governança. Com isso, os problemas de como tornar as instituições mais eficientes, e de como desenvolver e operar composições representativas de interesses de diferentes stakeholders, passam a ser enfrentados mais efetivamente. Os sistemas de governança, nessa linha, devem evoluir para contemplar interesses de acionistas minoritários, investidores institucionais, participação de empregados e de segmentos representativos de interesses da sociedade. Com a intensificação da participação desses diferentes grupos com influência sobre os rumos da organização, surge a necessidade de especificar seus direitos, esclarecer o papel de cada um no sistema de governança corporativa e estabelecer mecanismos capazes de proteger seus interesses individuais em consonância com interesses coletivos (TENEV; ZHANG; BREFORT, 2002, p. 1-2).

Percebe-se que, dos conceitos apresentados, embora a governança corporativa caminhe para a sua consolidação em empresas de capital aberto, que têm necessidade formal de prestação de contas em função das regras das bolsas de valores, ela pode e deve ser vista como importante instrumento de gestão estratégica das organizações em geral, sejam elas públicas ou privadas, pequenas ou grandes, de qualquer segmento da economia.

De acordo com Herbert Steinberg (2003), as empresas podem se encaixar em três estágios, no que tange à governança corporativa:

1) modelo atual-em que a empresa é gerenciada por poucos acionistas controladores com práticas informais de governança;

2) modelo emergente-em que a empresa passa a ser liderada por poucos acionistas controladores com governança formal e acesso ao capital para executar suas estratégias;

3) modelo de mercado - quando a empresa passa a ter controle compartilhado e governança formal com aspirações e capacidade financeira para competir globalmente. Nesse estágio, consolidam-se as práticas de compartilhamento de controle, valores e ideais, bem como se tornam mais maduros o conceito e a prática da responsabilidade social. 
Como o conceito de governança corporativa ainda não se encontra perfeitamente delineado, algumas proposições elementares são necessárias para desenvolver uma ordem de conhecimentos e de instrumentos para compreensão e condução dos rumos da empresa. Essas proposições elementares são os chamados princípios, cuja finalidade é suprir lacunas eimperfeições de conceitos e regras. Steinberg (2003) entende como princípios fundamentais da boa governança: a transparência (disclosure), a equidade (fairness), a prestação de contas (accountability), o cumprimento das leis (compliance) e a ética (ethics). Lodi (2000) também cita os quatro primeiros princípios citados anteriormente como aqueles que devem nortear a atuação de um conselho. No Brasil, os princípios básicos que inspiram o Código de Melhores Práticas do IBGC são: transparência, equidade, prestação de contas (accountability) e responsabilidade corporativa (IBGC, 2004).

De modo mais geral, a OCDE (2004) apresenta os princípios de governança corporativa divididos em cinco grandes áreas:

1) proteção dos direitos dos acionistas;

2) tratamento equânime dos acionistas, inclusive dos minoritários e dos estrangeiros;

3) reconhecimento do papel das partes interessadas na governança corporativa, conforme previsto em lei, e incentivo à cooperação ativa entre empresas e partes interessadas na criação de riquezas, empregos e na sustentação de empresas economicamente sólidas;

4) divulgação e transparência dos fatos relevantes para a empresa, inclusive situação financeira, desempenho, participação acionária e governança da empresa;

5) responsabilidades do conselho quanto à orientação estratégica da empresa, fiscalização efetiva da diretoria pelo conselho e a prestação de contas do conselho à empresa e aos acionistas.

Esses princípios são importantes para orientar esforços governamentais de avaliação e aperfeiçoamento da estrutura jurídica e institucional para a governança corporativa em seus países. Também proporcionam orientação e sugestões para bolsas de valores, investidores, empresas e outras entidades que desempenhem algum papel no processo de desenvolvimento de boa governança corporativa. Os princípios de governança corporativa são essencialmente voltados para realidades de empresas de capital aberto. Entretanto, sempre que considerados aplicáveis, podem também tornar-se ferramentas úteis para aperfeiçoar a governança corporativa em empresas não negociadas em bolsa (OECD, 2004), em empresas públicas ou organizações do terceiro setor.

\section{Melhores práticas e princípios}

Os princípios de governança oferecem padrões e referenciais para boas práticas, mas não são obrigatórios. Eles têm função de orientação na implementação, que pode ser adaptada às circunstâncias específicas de diferentes países e regiões (JOHNSTON, 2004,p. 4). A regulação da governança corporativa pode ser obtida formal ou informalmente por quatro mecanismos primários:

1) elaboração de leis (previsões estatutárias e lei comum);

2) concentração de stakeholders para aumentar as suas capacidades de controle e monitoração;

3) disciplina de mercado;

4) contrato formal entre stakeholders e a companhia.

Considerando a regulação por meio de leis e regras, há possibilidades de adoção de "regrasduras", dotadas de poder de coerção; "regras suaves", cuja adoção é voluntária; e "regras híbridas", que se situam entre esses dois extremos (ZADKOVICH, 2007). O grau de exigência dessas últimas regras depende de pressões contextuais incidentes sobre cada organização em função da ação de diferentes stakeholders.

Essas possibilidades de regulação por meio de leis e regras podem ser resumidas mediante caracterização das práticas de governança corporativa como "obrigatórias" ou "voluntárias". As "obrigatórias" são impostas sob pena de se incorrer em sanções ou caracterizar contravenção em caso de recusa em segui-las. As "voluntárias", cuja aplicação tem caráter discricionário, são destituídas de compulsão legal. Contudo, quando se trata de governança corporativa, é difícil de categorizar estritamente regimes como puramente obrigatórios ou voluntários, uma vez que 
a maior parte dos regimes apresenta características de ambos. Por isso, normalmente são caracterizados como "híbridos" (ZADKOVICH, 2007).

Ao analisar possibilidades de aceitação de regras formais ou informais, deve-se considerar que países necessitados de capital precisam aceitar normas de transparência contábil, probidade administrativa, prestação de contas, reformas econômicas e bancárias para atrair capitais. A resposta para esses problemas está na adoção dos Códigos de Melhores Práticas de Governança Corporativa (LODI, 2000). Os códigos da boa governança podem ser considerados como conjuntos de melhores práticas destinadas a orientar conselhos de diretores e aperfeiçoar outros mecanismos de governança. Tais códigos normalmente são projetados para dirimir deficiências no sistema de governança corporativa, recomendando conjuntos de normas e princípios para melhorar a transparência e o nível de responsabilização entre diretores (ZATTONI; CUOMO, 2008, p. 3). A adoção de tais códigos é fruto de recomendação, e não de imposição obrigatória. Entretanto, muitas vezes, as condições do próprio mercado geram pressões para a adoção, e a decisão depende da sensibilidade da organização para identificar e responder demandas de diferentes stakeholders para obter confiança e legitimidade.

O delineamento dos códigos de governança corporativa pode variar em função de diferentes regimes. Contudo, há quatro características básicas que a maioria deles compartilha. De modo geral, é comum:

1) que suas prescrições não sejam formal e fortemente interligadas;

2) que sejam emitidos por comitês especializados;

3) possuírem uma flexibilidade inata;

4) possuírem como elemento central o mercado, que tem duas funções: avaliar possíveis desvios da companhia e ter na execução do código por todos um meio de autoproteção (SEIDL, 2007).

Em termos de institucionalização de códigos de governança corporativa, Enrione et. al (2006), analisando 150 códigos, de 78 países, no período de 1974 a 2004, identificam quatro estágios desde sua implementação inicial até sua institucionalização, denominados como: choques iniciais precipitados, teorização, difusão, e reinstitucionalização.
Diante dessas características, a eficácia de um código depende, por um lado, da extensão em que se torna integrado em ciclos recursivos de observação mútua entre a corporação e vários stakeholders no campo e, de outro lado, de como se relaciona com outros esquemas de observação das práticas das corporações (SEIDL, 2007). Assim, as corporações modernas não são simplesmente vítimas de condições externas que lhes impuseram a governança corporativa, mas também ativamente criam e recriam as circunstâncias que tornaram a governança corporativa um imperativo (ROSSOUW, 2005, p. 32).

Com a finalidade de captar as mudanças ocorridas no meio empresarial, legislativo e regulatório e defini-las como parâmetros a serem seguidos pelas corporações, o Instituto Brasileiro de Governança Corporativa desdobra o seu Código de Melhores Práticas de Governança Corporativa em seis áreas:

1) propriedade de acionistas, quotistas, sócios;

2) conselho de administração que representa a propriedade;

3) gestão composta pelo executivo principal (CEO) e a diretoria;

4) auditoria independente;

5) fiscalização pelo conselho fiscal;

6) ética e conflito de interesses.

\section{Modelos de governança corporativa}

Diante da necessidade de ajuste a regras formais e informais peculiares a realidades locais, a diversidade de conceitos de governança corporativa é associada à diversidade dos modelos praticados em diferentes países e, em cada um deles, de sua evolução ao longo do tempo. A literatura técnica diferencia cinco modelos de governança: o anglosaxão, o alemão, o japonês, o latino-europeu e o latino-americano (ANDRADE; ROSSETTI, 2007).

Embora os conceitos gerais de governança sejam próximos, pautados em princípios relativamente aceitos pelas organizações nos vários continentes, pode-se afirmar que a sua operacionalização difere de país para país, ou entre grupos de países. O seguinte excerto bem demonstra a variedade de países e formas por meio das quais a governança acontece: 
nunca haverá um modelo único da boa governança corporativa, tampouco haverá um tipo de estrutura de conselho universalmente aceitável. Sem embargo, muito foi escrito sobre a convergência de modelos de governança ao redor do mundo, e há abundância de evidências de que muitos dos melhores códigos de práticas se desenvolveram ao longo da sobreposição de diferentes linhas. Contudo, as diferenças na governança de um país em relação a outro permanecem bastante substanciais para trazer perplexidade a todos, exceto ao observador mais diligente (SPENCER STUART, 2006, p. 5).

Diante disso, conhecer as particularidades dos modelos de governança dos diversos países onde se desenvolvem os negócios pode representar uma vantagem competitiva para aquelas organizações que almejam o sucesso. Conforme apontado por Johnson et al. (2007, p. 207), "há diferenças importantes entre os países na forma de propriedade das companhias, o que conduz a diferenças relativas ao papel, à composição e ao modus operandi da diretoria". Ainda, num patamar mais amplo, a governança corporativa passa a ser um veículo para incorporar preocupações sociais e ambientais no processo de tomada de decisão nos negócios, beneficiando não somente investidores, mas também empregados, consumidores e comunidades. Diante disso, a governança corporativa está cada vez mais relacionada com práticas de negócios e políticas públicas consonantes com peculiaridades de valores de stakeholders locais (GILL, 2008).

Com base em dez fatores de diferenciação, ou características definidoras, oriundas de quatro diferentes abordagens - de Prowse (1994), focada nas constituições dos conselhos de administração e em outros mecanismos internos de governança; de La Porta et al. (1998, 1999), que enfatiza a concentração da propriedade acionária e a proteção dos minoritários; de Berglöf (1990), que destaca a fonte de financiamento predominante; e de Franks e Mayer (1996), que analisa as diferenças atribuídas às forças de controle internas e externas, e suas eficiências - Andrade e Rossetti (2007, p. 336) constroem um quadro comparativo que agrupa os principais modelos de governança: o anglo-saxão, o alemão, o japonês, o latino-europeu e o latino-americano, descritos brevemente a seguir.

O modelo anglo-saxão tem como fundamentos a pulverização do controle acionário e a separação da propriedade e da gestão. Nesse modelo, tende a haver mobilizações tanto nos Estados Unidos quanto no Reino Unido, no Canadá e na Austrália, para a adoção de melhores práticas de governança. Dos conflitos de agência decorrentes das ações para monitorar os gestores e bloquear as práticas de gestão contrárias aos interesses dos acionistas figuram como as razões essenciais do ativismo de forças externas. $\mathrm{O}$ modelo tende a ser fortemente orientado para o mercado e também por ele monitorado.

No modelo alemão, o capital acionário das companhias é concentrado e o financiamento predominante é de origem bancária; o modelo de governança é predominantemente bank-oriented, e não market-oriented. Essas estruturas societárias e de capital levam à prevalência das forças internas de controle em relação às externas. Os conselhos de administração são fortalecidos e os propósitos de maximização do retorno total dos acionistas competem com os objetivos dos credores e de outros atores, levando o processo de governança na direção de um sistema de múltiplos interesses. Os conselhos de grandes empresas têm duas camadas, a de gestão (Vorstand) e a de supervisão (Aufsichtsrat).

No modelo japonês, os bancos exercem importante papel no financiamento e no monitoramento das empresas. A estrutura de capital das grandes corporações é concentrada, mas há um fator adicional de concentração peculiar do Japão: as ligações horizontais dos keiretsus - os conglomerados de negócios. As empresas conglomeradas possuem ligações horizontais entre si, pelas posses cruzadas de ações. Prevalecem, dessa forma, as forças internas de controle. A gestão se sobrepõe à propriedade e o modelo não está voltado para conflitos de agência.

Andrade e Rosseti (2007) comentam que, por razões culturais, pelas raízes comuns das instituições e pela formação do sistema empresarial, fundamentada em um misto de grandes grupos familiares e de empresas estatais, são bastante semelhantes as características de governança dos modelos latino-europeu e latino-americano. $\mathrm{Na}$ Espanha, na França, na Itália e em Portugal, que constituem o grupo latino-europeu, em virtude da predominância há três ou quatro gerações de famílias controladoras; já em razão da existência de bem arquitetados e rígidos acordos de acionistas, é típica a sobreposição da propriedade e da gestão.

Relativamente ao grupo latino-americano, a OECD destaca que o compartilhamento de carac- 
terísticas fundamentais entre as economias da região determina as reações do setor empresarial, não só em face das rápidas mudanças tecnológicas e do processo de globalização econômica, como também relativamente aos desafios que a governança corporativa impõe, inclusive nos seguintes aspectos: privatização; concentração patrimonial, controle definido e necessidades de capital; importância dos grupos industriais; reestruturação dos sistemas bancários; regionalização, internacionalização e importância de empreendimentos multilaterais; limitação dos mercados de capitais domésticos e a crescente importância de registros de valores mobiliários no exterior; fundos de pensão; tradições jurídicas e padrões de exequibilidade (OECD, 2003, p. 9).

De maneira geral, ao analisar as melhores práticas e princípios hoje difundidos em diferentes sistemas de governança corporativa, percebe-se relativa convergência em relação aos principais itens entendidos como relevantes na condução de uma entidade que vise a uma boa condição de governança. Contudo, Zattoni e Cuomo (2008, p. 2) enfatizam que, apesar dos benefícios de práticas de governança eficazes e a pressão de forças globais para sua adoção, a mudança de modelos de governança não é fácil por estarem inseridos em ambientes institucionais nacionais. A necessária complementaridade entre práticas de governança pode ter a convergência dificultada por:

1) alteração de um mecanismo sem a mudança de outros que podem dissipar os benefícios que resultam da sua interação;

2) ser difícil transformar muitas instituições ao mesmo tempo e de modo coordenado.

\section{A governança corporativa no Brasil}

Não são poucos os casos de má gestão de organizações conhecidos nos últimos anos, seja no Brasil ou no mundo. O cumprimento de boas práticas de governança corporativa colabora para que os interesses de todos os assim chamados stakeholders de uma organização sejam atendidos. Percebe-se no Brasil uma preocupação cada vez maior por parte desses stakeholders, em particular por parte dos acionistas de uma organização, em melhor conhecer e, principalmente, reconhecer o atendimento a essas práticas.

No Brasil, com o lançamento do programa Novo Mercado (NM), houve prescrição de rigorosos padrões de governança corporativa e, com isso, tem-se obtido sucesso na atração de investimentos. Houve fortalecimento da confiança do investidor na integridade da forma corporativa e naqueles que supervisionam seu investimento. Regras para regular transações que envolvem conflitos de interesses têm promovido um ambiente transparente e participantes de mercado bem informados. Nessa linha, o NM tem demonstrado abertura, transparência, e existência de boa governança (MILLSTEIN, 2005, p. 6-7). Nesse sentido, Silveira (2008a) afirma que:

atualmente, há uma sensação de que a governança corporativa é um ponto forte do mercado de capitais nacional. O tema é visto como uma espécie de problema bem resolvido, principalmente com o advento do Novo Mercado $(\mathrm{NM})$, que, na visão de muitos, instituiu um selo de garantia às companhias deste segmento. Sem dúvida, esta sensação é corroborada por algumas evidências concretas.

Contudo, a questão da governança corporativa está longe de ser resolvida no Brasil, uma vez que o NM é uma condição necessária, mas não suficiente para adoção das melhores práticas de governança. Mesmo considerando suficiente o NM, há que se considerar que menos de um quarto das empresas da bolsa (apenas 100 das 452) compõem o NM. Em termos de capitalização de mercado da Bovespa há representatividade de apenas um quinto das empresas. Outro fator que aponta para a fragilidade da institucionalização da governança corporativa no País é que, dentre as vinte maiores do País em valor de mercado, que representam dois terços da capitalização de mercado da Bovespa, apenas três faziam parte do NM no final de junho de 2008: Banco do Brasil, Redecard e MMX. Finalmente, em pesquisas recentes o Brasil ainda não aparece como um país avançado em governança corporativa (SILVEIRA, 2008c).

Nessa direção também aponta o estudo de Black et al. (2008), realizado por meio de um survey com organizações brasileiras com ações negociadas na Bolsa de Valores de São Paulo, quando foram obtidas 116 respostas, que representaram $32 \%$ da 
população estudada. Dentre as conclusões desse trabalho, destacaram-se as seguintes constatações:

1) a notável fraqueza de governança em termos de independência do conselho de administração;

2) a transparência financeira atrás de padrões mundiais;

3) comitês de auditoria ainda são incomuns;

4) há um elevado percentual de empresas privadas brasileiras $(74 \%)$ que emitem ações sem direito a voto.

Considerando o contexto brasileiro mais amplo, "há um vasto número de empresas de grande porte e com práticas incipientes de governança", pois, das aproximadamente 45 mil companhias de médio e grande porte apontadas pelo IBGE, somente 452 (cerca de 1\%) delas são listadas em bolsa. Assim, em termos de representatividade, "O número de empresas no NM corresponde a ínfimos $0,3 \%$ das grandes empresas do país" (SILVEIRA, 2008c).

Em relatório recente, a Governance Metrics International enfatizou que, no Brasil, o NM teve um impacto importante para rejuvenescer o mercado de capital que tinha estagnado no final dos anos 1990. O NM foi projetado para promover a transparência e instigar confiança. Entretanto, a sua evolução e ampliação requer que as companhias se inclinem a ultrapassar voluntariamente as exigências da legislação brasileira existente e passem a adotar padrões de transparência e meios de proteção especial para investidores minoritários, a exemplo de práticas europeias e estadunidenses (GMI, 2008a).

Quando se tem em conta a necessidade de avanços da governança corporativa no Brasil, Silveira (2008a, p. 2) destaca que o atual desafio é ir além dos requisitos do Novo Mercado, uma vez que:
1) o mercado ainda não testou de fato a qualidade das práticas de governança das empresas pertencentes ao Novo Mercado, principalmente em função do excelente desempenho da bolsa no período de 2004 a 2007; 2) a governança não se encerra com a adesão ao Novo Mercado, já que diversas práticas não previstas neste segmento de listagem precisam ser adotadas ou aprimoradas; 3) a avaliação das práticas de governança deve evoluir de uma abordagem meramente estrutural (de "marcar caixinhas") para modelos que propiciem uma compreensão correta do seu nível de efetividade e de geração de valor aos negócios.

Em termos de cenário geral, ressalvadas algumas iniciativas ainda pontuais de sucesso, as evidências empíricas demonstram grande fragilidade da governança corporativa no Brasil. O Instituto Brasileiro de Governança Corporativa, por meio de avaliação de todas as empresas listadas em bolsa em 2007, obteve média geral abaixo de 9 pontos numa escala que varia de 0 a 20 (SILVEIRA, 2008c), conforme sintetizado na Tabela 1.

Em âmbito internacional, considerando a posição do Brasil no GMI Country Ranking, que varia de 0 a 10 pontos, publicado pela Governance Metrics International (GMI, 2006, 2007, 2008b, 2009), ocorreram melhorias quando comparado com a média de um conjunto de 26 países emergentes. Como pode ser verificado na Tabela 2 , o Brasil vem se posicionando, de modo consistente, muito próximo da média daquele conjunto entre 2007 e 2009, mantendo-se em torno de 4 pontos na escala. Contudo, ainda está bem distante dos países líderes, que superam 7 pontos. O Gráfico 1 facilita a visualização da posição do Brasil em relação ao grupo de países emergentes e outros países selecionados no ano de 2009.

Tabela 1 - Resultados do Prêmio IBCG de Empresas - 2005, 2006 e 2007

\begin{tabular}{ccccccccc}
\hline Ano & Média & Desvio-padrão & Mínimo & $\mathbf{1}^{\mathbf{0}}$ Quartil & Mediana & $\mathbf{3}^{\mathbf{0}}$ Quartil & Máximo & $\begin{array}{c}\text { Amostra } \\
\text { (empresas) }\end{array}$ \\
\hline 2007 & 8,8 & 3,50 & 1,5 & 6,0 & 8,5 & 11,5 & 17,0 & 366 \\
2006 & 7,9 & 3,04 & 1,5 & 5,5 & 7,5 & 9,5 & 17,0 & 343 \\
2005 & 7,7 & 2,65 & 2,0 & 6,0 & 7,0 & 9,0 & 16,0 & 378 \\
\hline
\end{tabular}

Fonte: SILVEIRA, 2008c. 
Tabela 2 - Ranking de práticas de governança corporativa, países e grupos de países selecionados, 2006-2009

\begin{tabular}{lllll}
\hline & $\mathbf{2 0 0 6}$ & $\mathbf{2 0 0 7}$ & $\mathbf{2 0 0 8}$ & $\mathbf{2 0 0 9}$ \\
\hline Reino Unido & 7.30 & 7.40 & 7.28 & 7.36 \\
Canadá & 7.33 & 7.31 & 7.38 & 7.35 \\
Austrália & 7.24 & 7.31 & 7.25 & 7.32 \\
EUA & 7.22 & 7.25 & 7.25 & 7.18 \\
Nova Zelândia & 6.51 & 6.79 & 6.50 & 6.42 \\
Alemanha & 5.66 & 6.15 & 5.73 & 5.73 \\
Itália & 5.64 & 5.95 & 5.32 & 5.60 \\
França & 4.47 & 4.62 & 4.43 & 4.53 \\
Portugal & 4.36 & 4.64 & 4.33 & 4.38 \\
Mercados emergentes & 4.30 & 4.46 & 4.09 & 4.09 \\
Brasil & 3.23 & 4.08 & 4.18 & 4.01 \\
Espanha & 4.91 & 4.73 & 4.00 & 3.77 \\
Japão & 4.01 & 4.26 & 3.34 & 3.32 \\
México & 5.10 & 4.20 & 3.04 & 2.48 \\
\hline
\end{tabular}

Fonte: GOVERNANCE METRICS INTERNATIONAL -GMI, 2006, 2007, 2008b, 2009.

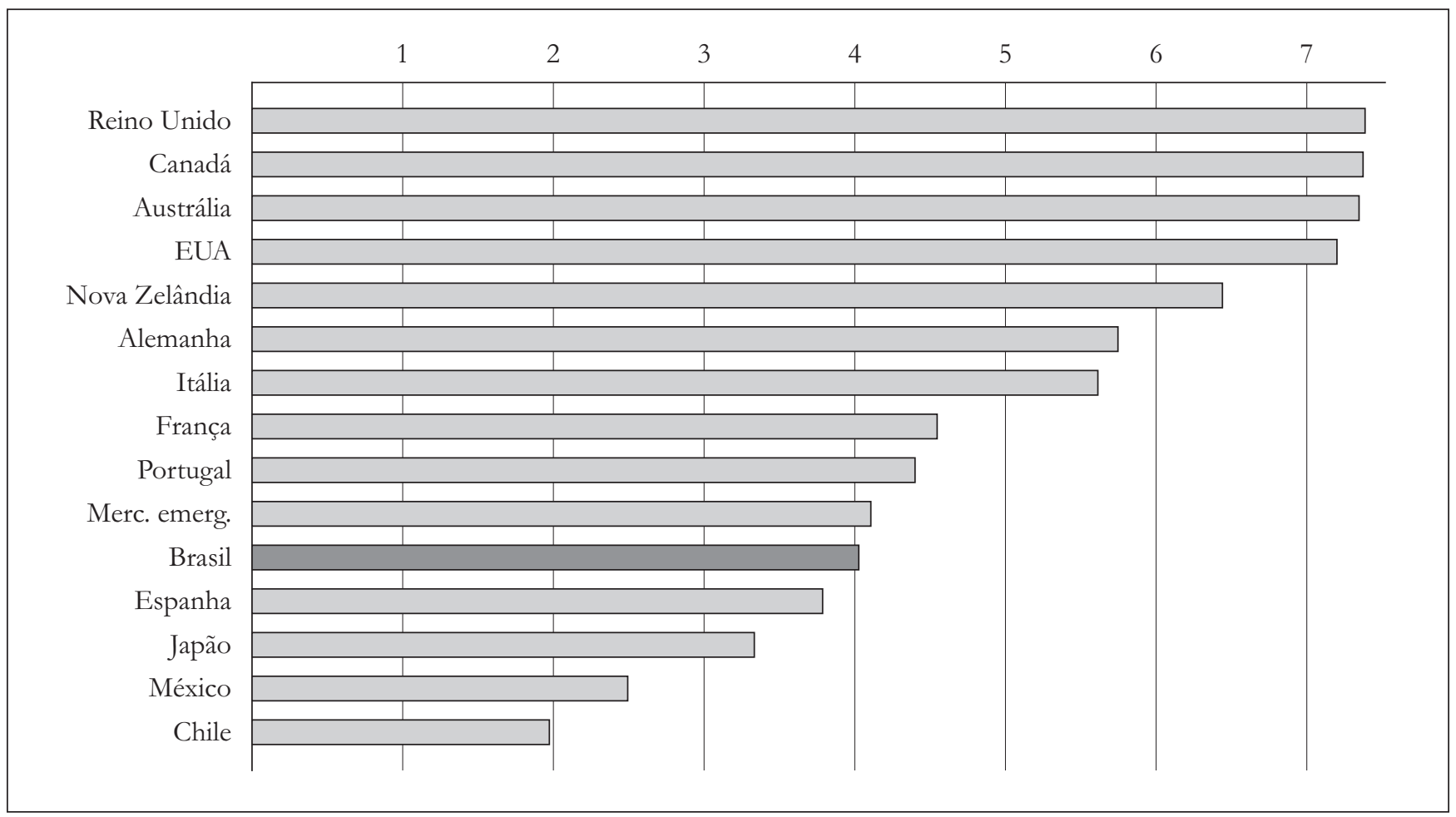

Gráfico 1 - Ranking de práticas de governança corporativa, países e grupos de países selecionados, 2009 Fonte: GOVERNANCE METRICS INTERNATIONAL - GMI, 2009. 
Inegavelmente, ainda há um longo caminho a percorrer para o desenvolvimento e a institucionalização de boas práticas de governança no Brasil, principalmente quando comparadas com aquelas identificadas nos países anglo-saxões. Contudo, ressalvada a questão da representatividade da abrangência da adoção de boas práticas, nos últimos anos surgiram alguns indicadores que apontam para melhorias na governança corporativa.

\section{Conclusões}

Embora o conceito de governança corporativa possa ter nascido com o objetivo de fornecer maior nível de transparência em relação às empresas de capital aberto, com ações negociadas em bolsas de valores, o conceito é hoje entendido como de fundamental importância para o sucesso das organizações em geral. No espaço que compreende as relações entre organizações, seus controladores, gestores e outros stakeholders, sempre existirão novas possibilidades e novos desafios para o fortalecimento das próprias organizações e dos mercados nos quais elas atuam.

Portanto, é necessário que o tema governança corporativa seja continuamente pesquisado, e se busque entender as razões dos diferenciais de valoração e desempenho das empresas no mercado. $\mathrm{E}$, quaisquer que sejam as origens dessas eventuais diferenças, é importante que sejam levados em consideração, além de questões de ordem ética, fatores relacionados ao mercado, à produtividade, ao posicionamento estratégico, e outros que apresentem relações diretas com o desempenho estratégico da organização. Nessa direção, constatações de acadêmicos e de praticantes têm indicado que

a competitividade estratégica da empresa é aumentada quando os mecanismos de governança levam em consideração os interesses de todas as partes interessadas. Embora a idéia esteja sujeita a discussões, alguns acreditam que as empresas eticamente responsáveis concebem e usam mecanismos de governança que atendem aos interesses de todos [...]. Apenas quando a governança corporativa adequada for exercida, poderão ser formuladas e implementadas estratégias que irão ajudar a empresa a atingir a competitividade estratégica e obter retornos acima da média (HITT; IRELAND; HOSKINSON, 2008, p. 297).
Tornar as instituições mais transparentes, responsáveis e capazes de se reportar com eficácia aos seus gestores, sejam eles de origem pública ou privada, de empresas ou universidades, constitui um desafio atual. Levar o tema da governança corporativa às organizações significa, entre outros aspectos, compreender que elas são regidas por diversas instâncias, cada uma com seus próprios critérios de gestão e com padrões indicativos do que seja aceitável no conjunto de resultados obtidos por companhia.

Especificamente no caso da governança corporativa no Brasil, à exceção de algumas iniciativas pontuais de sucesso, as evidências empíricas demonstram grandes fragilidades. Considerando a amplitude e o potencial do mercado para surgimento de organizações com escopo de atuação global, no contexto brasileiro há um longo caminho a percorrer para o desenvolvimento e a institucionalização de boas práticas de governança, principalmente quando comparadas com aquelas identificadas nos países anglo-saxões.

\section{Referências}

ANDRADE, A.; ROSSETTI, J. P. Governança corporativa: fundamentos, desenvolvimento e tendências. 3. ed. São Paulo: Atlas, 2007.

BERGLÖF, E. Corporate control and capital structure: essays on property rights and financial contracts. Stockholm: Stockholm School of Economics - Institute of Economics Research (EFI) and the Institute of International Business (IIB), 1990.

BLACK, B. S.; CARVALHO, A. G. de; GORGA, E. An overview of Brazilian corporate governance. Ithaca: Cornell Legal Studies, 2008.

BRENNAN, D. M. Policy and corporate governance in the wake of Enron's collapse. Social Text, New York, v. 21, n. 4, p. 35-50, 2003.

BROWNE, J. Corporate codes of conduct. In: BEVIR, M. (Org.). Encyclopedia of Governance. Thousand Oaks, CA: Sage Publications, 2007. v. 1. p. 163-164.

CADBURY REPORT. The report of the Committee on the Financial Aspects of Corporate Governance. London: The Committee on the Financial Aspects of Corporate Governance and Gee and Co., 1992. 
CASTIGLIONE, D. Accountability. In: BEVIR, M. (Org.). Encyclopedia of Governance. Thousand Oaks, CA: Sage Publications, 2007. v. 1, p. 1-7.

CIFRINO, D. A. et al. An insider's guide to going public: a guide to initial public offerings and life as a public company. 2nd ed. Chicago, IL: RR Donnelley, 2004.

ENRIONE, A.; MAZZA, C.; ZERBONI, F. Institutionalizing codes of governance. American Behavioral Scientist, v. 49, n. 7, p. 961-973, 2006.

FRANKS, J.; MAYER, C. Hostile takeovers and the correction of managerial failure. Journal of Financial Economics, New York, v. 40, n. 4, p. 163-181, 1996.

GILL, A. Corporate governance as social responsibility: a research agenda. Berkeley Journal of International Law, New York, v. 26, n. 2, p. 452-478, 2008.

GOVERNANCE METRICS INTERNATIONAL - GMI. GMI country rankings. Report. New York: GMI, 2006.

GOVERNANCE METRICS INTERNATIONAL - GMI. GMI country rankings. Report. New York: GMI, 2007.

GOVERNANCE METRICS INTERNATIONAL - GMI. Brazil: corporate governance and economic development. New York: GMI, 2008a.

GOVERNANCE METRICS INTERNATIONAL - GMI. GMI country rankings. Report. New York: GMI, 2008b.

GOVERNANCE METRICS INTERNATIONAL - GMI. GMI country rankings. Report. New York: GMI, 2009.

HITT, M. A.; IRELAND, R. D.; HOSKINSON, R. E. Administração estratégica: competitividade e globalização. 2. ed. São Paulo: Thomson Learning, 2008.

INSTITUTO BRASILEIRO DE GOVERNANÇA CORPORATIVA - IBGC. Código das melhores práticas. 2. ed. São Paulo: IBGC, 2004.

JOHNSON, G.; SCHOLES, K.; WHITTINGTON, R. Explorando a estratégia corporativa. 2. ed. Porto Alegre: Bookman, 2007.

JOHNSTON, D. J. Foreword. In: ORGANISATION FOR ECONOMIC CO-OPERATION AND DEVELOPMENT - OECD. Principles of corporate governance. 2nd ed. Paris: OECD Publishing, 2004. p. 66.

KOLK, A. Sustainability, accountability and corporate governance: exploring multinationals' reporting practices. Business strategy and the environment, New York, v. 17, n. 1. p. 1-15, 2008.
RISK ADVISORY SERVICES. $2^{\circ}$ estudo sobre as melhores práticas de governança corporativa no Brasil e nos Estados Unidos. São Paulo: KPMG, 2007. Base Relatório Anual 20-F.

LA PORTA, R.; LOPEZ-DE-SILANE, F; SHLEIFER, A. Corporate ownership around the world. Cambridge, MA: Working Papers; National Bureau of Economic Research, 1998.

LA PORTA, R.; LOPEZ-DE-SILANE, F.; SHLEIFER, A. Corporate ownership around the world. The Journal of Finance, New York, v. 54, n. 2, p. 471-517, 1999.

LIN, C. Corporatisation and corporate governance in China's economic transition. Economics of Planning, New York, v. 34, n. 1, p. 5-35, 2001.

LODI, J. B. Governança corporativa: o governo da empresa e o conselho de administração. 2. ed. Rio de Janeiro: Campus, 2000.

MAYNTZ, R. Common goods and governance. In: HERITIER, A. (Org.). Common goods. Reinventing European and international governance. Lanham: Rowman \& Littlefield Publishers, 2001. p. 15-27.

MAYNTZ, R. Mechanisms in the analysis of macro-social phenomena. Köln: Max Planck Institute for the Study of Societies, 2003. p. 1-21. MPIfG Working Paper 03/3.

MEYER Jr., V. Enfrentando as crises: competição e estratégias. In: MEYER Jr., V.; MURPHY, J. P. (Org.). Liderança e gestão da educação superior católica nas Américas. Curitiba: Champagnat, 2007. p. 265-295.

MEYER,J. W.;JEPPERSON, R. L. The 'actors' of modern society: the cultural construction of social agency. Sociological Theory, New York, v. 18, n. 1, p. 100-120, 2000.

MILLSTEIN, I. M. Laying the groundwork for economic growth. Economic Perspectives, New York, v. 10, n. 1, p. 4-7, 2005.

ORGANISATION FOR ECONOMIC CO-OPERATION AND DEVELOPMENT - OECD. White Paper on corporate governance in Latin America. Paris: White Paper, 2003.

ORGANISATION FOR ECONOMIC CO-OPERATION AND DEVELOPMENT - OECD. Principles of corporate governance. Paris: White Paper, 2004.

OMAN, C.; BLUME, D. Corporate governance: the development challenge. Economic Perspectives, v. 10, n. 1, p. 16-19, 2005. 
PRABHAKAR, R. Corporate governance. In: BEVIR, M. (Org.). Encyclopedia of Governance. Thousand Oaks, CA: Sage Publications, 2007. v. 1, p. 165-168.

PROCOPIUCK, M.; FREY, K. Articulações organizacionais em redes de políticas públicas no ciberespaço: o caso da política de difusão social de TICS em Porto Alegre e Curitiba. Organizações \& Sociedade, v. 16, n. 51, p. 687-706, 2009.

PROWSE, S. Corporate governance in an international perspective: a survey of corporate mechanisms among large firms in the United States, the UK, Japan and German. BIS Economic Papers, n. 41. Basel: Bank for International Settlements: Monetary and Economic Department, 1994. p. 82.

ROSSOUW, G. J. Business ethics and corporate governance: a global survey. Business Society, v. 44, n. 1, p. 32-39, 2005.

SCOTT, W. R. Organizations: rational, natural and open systems. 3rd ed. Englewood Cliffs, NJ: Prentice-Hall, 1992. p. 414.

SEIDL, D. Standard setting and following in corporate governance: an observation-theoretical study of the effectiveness of governance codes. Organization, New York, v. 14, n. 5, p. 705-727, 2007.

SILVEIRA, A. D. M. D. Os desafios da governança: ir além do novo mercado. Valor Econômico. 2008a. Disponível em: <http://www.riobravo.com.br/noticias/ conteudo.asp?id=9540,07/10/2008>. Acesso em: 7 out. 2008.

SILVEIRA, A. D. M. D. Desafios da governança:iralém do Novo Mercado (II). Valor Econômico, 15 ago. 2008. Disponível em: <http://www.valoronline.com.br/valor economico/285/eueinvestimento/49/Desafios + da $+>$. Acesso em: 15 ago. 2008b.

SILVEIRA, A. D. M. D. Governança corporativa: impactos no crescimento e desenvolvimento econômico. In: CONGRESSOBRASILEIRODE CONTABILIDADE, 18., 2008, Gramado. Anais... Gramado: Congresso Brasileiro de Contabilidade, 2008c.

SPENCER STUART. Governance lexicon: a diretor's guide to corporate governance around the world. 2nd ed. Chicago, IL: Spencer Stuart, 2006.

STEINBERG, H. A dimensão humana da governança corporativa: pessoas criam as melhores e as piores práticas. 2. ed. São Paulo: Gente, 2003.
SULLIVAN, J.; SAMBUNARIS, G. Creating a sustainable corporate environment. Economic Perspectives, New York, v. 10, n. 1, p. 22-24, 2005.

TENEV, S.; ZHANG, C.; BREFORT, L. Corporate governance and enterprise reform in China: building the institutions of modern markets. 2nd ed. Washington, DC: World Bank and the International Finance Corporation, 2002.

TSOUKAS, H. Introduction: chaos, complexity and organization theory. Organization, New York, v. 5, n. 3, p. 291-313, 1998.

WILLIAMSON, O. E. Corporate finance and corporate governance. Journal of Finance, New York, v. 43, n. 3, p. 567-591, 1988.

YOUNG, M. N. et al. Corporate governance in emerging economies: a review of the principal-principal perspective. Journal of Management Studies, New York, v. 45, n. 1, p. 196-220, 2008.

ZADKOVICH, J. Mandatory requirements, voluntary rules and please explain: a corporate governance quagmire. Deakin Law Review, v. 12, n. 2, p. 23-39, 2007.

ZATTONI, A.; CUOMO, F. Why adopt codes of good governance? A comparison of institutional and efficiency perspectives. Corporate Governance: An International Review, New York, v. 16, n. 1, p. 1-15, 2008.

Recebido: 11/08/2010 Received: 08/11/2010

Aprovado: 05/11/2010 Approved: 11/05/2010 